\title{
STIMULASI KEMAMPUAN BERPIKIR KRITIS MELALUI PEMBELAJARAN BERBASIS MASALAH PADA PENDIDIKAN JASMANI
}

\author{
Mesa Rahmi Stephani \\ STKIP Pasundan Cimahi \\ email : mesarahmistephani@gmail.com
}

\begin{abstract}
Abstrak
Artikel ini disajikan melalui kajian literatur yang berusaha memaparkan bagaimana proses kemampuan berpikir kritis dapat distimulasi melalui pembelajaran berbasis masalah pada pembelajaran penjas. Penulis mencoba memaparkan proses stimulasi berpikir kritis dari berbagai perspektif, diantaranya perspektif neurologi, sosiokultural, dan keadaan awal siswa serta berbagai hasil penelitian terkait berpikir kritis pada konteks pendidikan jasmani. Para guru penjas dapat mengimprovisasi kemampuan berpikir kritis melalui pembelajaran penjas berbasis masalah, dengan memperhatikan faktor-faktor pendukung lainnya seperti keadaan awal peserta didik meliputi IQ, gaya belajar, dsb. Serta aspek sosiokultural tempat peserta didik berinteraksi perlu menjadi pertimbangan dan perhatian, agar pembelajaran dapat berkualitas dan berdampak terhadap perkembangan peserta didik secara holistik.
\end{abstract}

Kata Kunci : Berpikir kritis, pendidikan jasmani

\section{PENDAHULUAN}

Pesatnya kemajuan teknologi memberikan banyak kemudahan bagi berbagai sendi kehidupan. Berbagai macam informasi sangat mudah masuk dan diakses oleh orang diberbagai belahan dunia termasuk Indonesia. Masyarakat harus mampu memilah dan mengkritisi berbagai macam berita yang jika tidak cermat dalam memilah informasi akan memberikan dampak negatif bagi pembaca khususnya. Perkembangan zaman dan tuntutan persaingan yang demikian pesat harus segera ditindaklanjuti oleh pemerintah. Untuk mempersiapkan Sumber Daya 
Manusia (SDM) yang berdaya saing tinggi dan berkarakter, pendidikan merupakan jawaban untuk menjawab tantang itu.

Kurikulum merupakan arah pelaksanaan pendidikan di sekolah, dan merupakan upaya pemerintah untuk mencapai tujuan pendidikan nasional. Perubahan kurikulum tentunya memiliki arti bahwa tuntutan dan kebutuhan kompetensi Sumber Daya Manusia (SDM) selalu berubah sesuai dengan perubahan dan tantangan zaman. Perubahan kurikulum 2013 yang menekankan perubahan pada aspek proses pembelajaran yang saintifik tentunya memberikan tantangan tersendiri bagi mata pelajaran Pendidikan Jasmani (Penjas). Proses pembelajaran saintifik erat kaitannya dengan mata pelajaran Pengetahuan Alam. Namun, proses berpikir saintifik diperlukan dalam segi kehidupan, termasuk kehidupan sosial, sehingga proses pembelajaran saintifik tidak terpaku pada pembelajaran di kelas ataupun laboratorium. Mata pelajaran penjas yang memiliki ciri khas pada aktivitas gerak dan dilaksanakan di luar ruang kelas, tentu memiliki tantangan tersendiri dalam mengimplementasikan pembelajaran berbasis saintifik melalui aktivitas gerak.

Kemampuan berpikir kritis merupakan salah satu kompetensi yang dituju melalui kurikulum 2013 ini, khususnya pada tingkat SMP dan SMA. Tentu kompetensi ini sangatlah penting dimiliki oleh lulusan, karena merupakan dasar untuk mengidentifikasi masalah serta mampu menyelesaikan masalah sehingga dapat menggapai kesuksesan dalam bidangnya masing-masing.

\section{PEMBAHASAN}

\section{Konsep Kemampuan Berpikir Kritis}

Kemampuan berpikir kritis sangatlah penting bagi setiap individu, sehingga di dalam proses pendidikan harus memberikan pengalaman belajar yang bermakna bagi peserta didik, salah satunya berpikir kritis. Ennis (1985, hlm 45) mengemukakan bahwa "Critical thinking is reflective and reasonable thinking that is focused on deciding what to believe or do". Manusia telah dikaruniakan akal fikir untuk digunakan dalam menghadapi berbagai permasalahan dalam hidup ${ }^{c e}$. Maka, manusia wajib berpikir dalam menghadapi berbagai persoalan. Kuswana (2011, hlm. 3) menjelaskan proses berpikir yaitu:

Proses berpikir merupakan urutan kejadian mental yang terjadi secara alamiah atau terencana dan sistematis pada konteks ruang, waktu, dan media yang digunakan, serta menghasilkan suatu perubahan terhadap objek yang memengaruhinya. Proses berpikir merupakan peristiwa 
mencampur, mencocokkan, menggabungkan, menukar, dan mengurutkan konsep-konsep, persepsi-persepsi, dan pengalaman sebelumnya.

Secara sederhana Ennis (1985, hlm. 45) mengemukakan bahwa "Critical thinking is reflective and reasonable thinking that is focused on deciding what to believe or do". Berpikir kritis sangatlah penting dimiliki oleh setiap siswa, agar siswa senantiasa mampu menyelesaikan permasalahan dengan efektif dan efisien. Menurut Gallahue (1996, hlm. 73) "Critical thinking, therefore is a form of cognitive accountability based on concept information, in which the learner notes relationships and makes conscious decisions based on established criteria". Proses berpikir kritis dapat dilhat pada gambar 1 berikut ini:

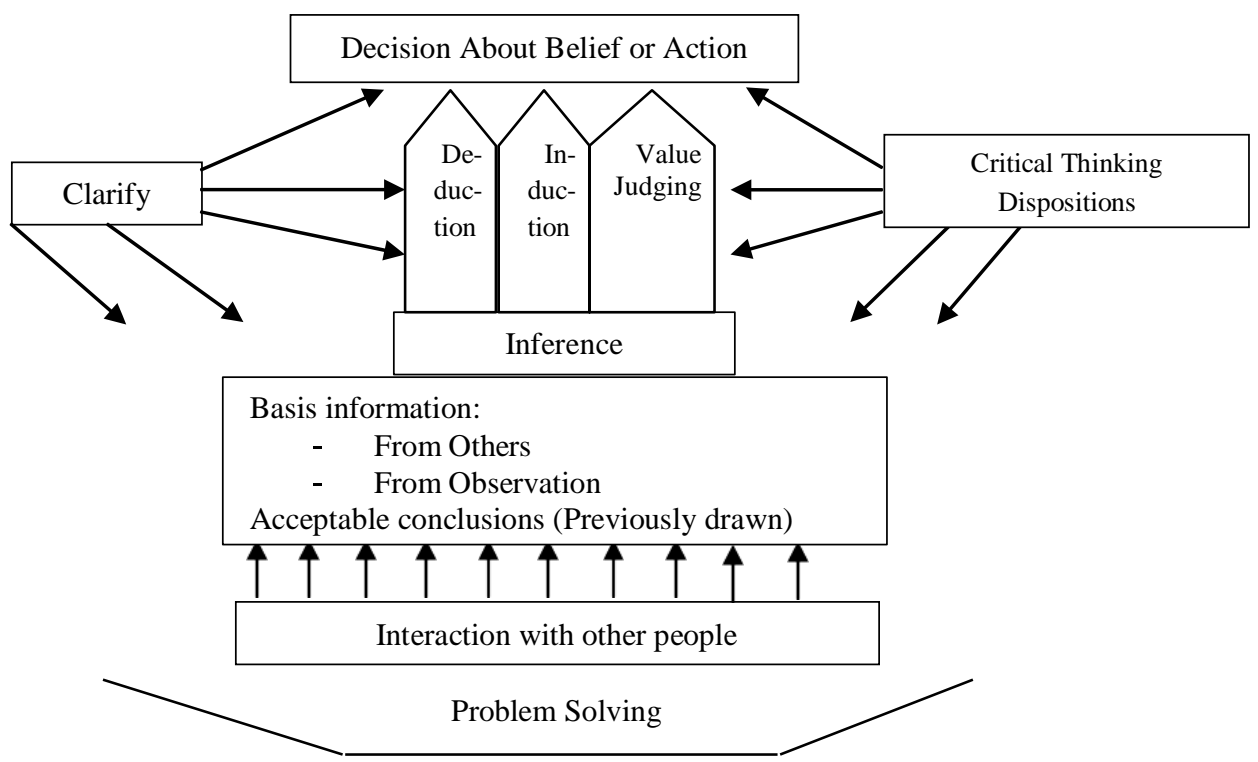

Gambar 1

The Process of Deciding What to Believe or Do

(Sumber: Ennis, Robert H. (1985) A Logical Basis for Measuring Critical Thinking Skills.

Copyrigth (C) 1985 by Association For Supervision and Curriculum Development)

Pada Gambar 1 menunjukkan bahwa berpikir kritis terjadi dalam sebuah proses pemecahan masalah. Tishman dan Perkins (1995; dalam 
Walkuski, 2013, hlm. 84) mendefinisikan berpikir kritis dalam pendidikan jasmani dalam pengertian lebih luas. Tishman dan Perkins menganggap berpikir kritis sebagai suatu proses yang mencakup semua tingkat kemampuan dan pengalaman sehari-hari siswa. Mereka memandang konsep berpikir kritis termasuk ke dalam berpikir kreatif di mana seorang individu berjalan melalui proses berpikir dari berbagai kemungkinan sebagai solusi terhadap sebuah masalah. McBride (1992; dalam Walkuski, 2013, hlm. 83) menyatakan bahwa :

Proposed an initial model of critical thinking in physical education. In this model, critical thinking in physical education can be visualized as loosely configures four-step process: cognitive organizing, cognitive action, cognitive outcomes, and psychomotor outcomes.

Pada pembelajaran kognitif siswa perlu diberikan kesempatan dalam kegiatan inkuiri atau pengamatan. McBride dkk. (1990, hlm 198) menjelaskan bahwa :

However, in order to involve critical thinking, students first must be given opportunity to inquire. Only during inquiry dan critical thinking skills be activated through such cognitive functions as comparing, contrasting, categorizing, hypothesizing, synthesizing, extrapolating, and problem solving.

Pembelajaran penjas yang mempunyai peran khusus dalam penyampaian nilai-nilai pendidikan melalui gerak, dapat pula memberikan kontribusi terhadap kemampuan berpikir siswa . Walkuski (2013, hlm 87) menjelaskan bahwa :

Critical thinking does have a place in the psychomotor-domain. Physical education and sport environments can provide a supportive environtment for individual to learn how to think critically...Students can be challenged to produce unique solutions to movements problems, create new versions of game, and think through issues related to fitness and health.

Kemudian menurut Cottrell (2005, hlm. 2) berpikir kritis adalah sebuah proses kompleks pertimbangan yang melibatkan berbagai keterampilan dan sikap. Hal itu meliputi: mengidentifikasi posisi, argumen, dan kesimpulan orang lain; Mengevaluasi bukti untuk sudut 
pandang alternatif; menimbang argument yang bertentangan dan bukti yang cukup; mampu membaca apa yang tersirat, melihat di balik permukaan, dan mengidentifikasi asumsi yang salah atau tidak adil; mengenal teknik yang digunakan untuk membuat posisi tertentu lebih menarik daripada yang lain, seperti logika salah dan perangkat persuasif; mencerminkan isu-isu dengan cara struktur, membawa logika dan wawasan harus menanggung; menarik kesimpulan tentang apakah argumen yang valid dan dapat dibenarkan, berdasarkan bukti yang baik dan asumsi yang masuk akal; menyajikan sudut pandang secara terstruktur, jelas, cara yang memberikan alasan untuk meyakinkan orang lain.

\section{Konsep Belajar Kognitif pada Pembelajaran Gerak}

Pada pembelajaran gerak terjadi proses kogntif yang mana hasil dari proses kognitif akan tercermin pada gerak. Proses kognitif akan terjadi manakala siswa dihadapkan pada suatu permasalahan. Konsep belajar kognitif berbeda dengan konsep belajar akademik, karena seringkali kognitif dihubungkan dengan akademik. Gallahue (1996, hlm.

73) menegaskan bahwa:

Cognitive concept learning is not to be confused with academic concept learning. Academic concept learning deals specifically with the traditional subject matter areas of math, language arts, science, and the like. Cognitive concept learning is much more inclusive term that includes academic learning as only one of its several components.

Pada pembelajaran gerak terdapat situasi yang menstimulasi proses pembelajaran pada aspek kognitif siswa. Salah satu contohnya yaitu pada saat pembelajaran passing bola basket, siswa mengamati temannya yang sedang melakukan gerakan chest pass. Siswa mengamati gerakan tersebut mulai dari kepala hingga kaki. Siswa memperhatikan bagaimana gerakan chest pass tersebut dilakukan agar bola dapat di passing ke temannya dengan baik. Pada proses mengamati inilah kognisi diaktifkan, untuk kemudian menghasilkan gerakan chest pass. Kemudian guru memberikan sebuah permasalahan gerak yaitu bagaimana cara melakukan passing kepada teman yang sedang dijaga oleh lawan. Pada tahap ini terjadi proses pemecahan masalah melalui berpikir kritis. Gallahue (1996, hlm. 73) mengemukakan bahwa "Cognitive concept learning provides children with the tools for critical thinking. It uses movement activities to aid retention, recall, decision making, and application". 
Proses pembelajaran gerak pada pembelajaran passing terjadi sebuah pembelajaran kognitif manakala siswa dihadapkan pada proses pemecahan masalah untuk membuat keputusan serta dihadapkan pada beberapa alternatif jawaban yang ada. Pada proses inilah siswa berada pada tingkat pemikiran yang lebih tinggi, karena siswa mempertimbangkan beberapa konsekuensi dari setiap pilihan jawaban. Siswa dihadapkan pada situasi pengambilan keputusan yang kemungkinan kesalahannya paling sedikit. Mengenai hal ini dapat dikaitkan dengan teori belajar kognitif yang diungkapkan oleh Gallahue (1996, hlm. 74) yaitu "Cognitive learning theory views learning as a process that involves experimentation, exploration, and individual decision making; it is a process that necessitates the reconstruction of incorrect events into a new, correct, whole".

\section{Pertimbangan Olahraga Bola basket sebagai Media Pembelajaran Kognitif dalam Menstimulasi Kemampuan Berpikir Kritis Siswa Tingkat SMP.}

Bola basket merupakan olahraga yang dimainkan secara berkelompok dengan jumlah pemain lima orang setiap kelompoknya. Bola basket merupakan olahraga yang populer dikalangan remaja. Sesuai dengan perkembangan siswa SMP yang rata-rata berusia lebih dari 12 tahun. Pada usia ini, para ahli mengkategorikan ke dalam masa remaja awal. Pada masa ini, perkembangan kognitif remaja berada pada tahap formal operasional. Menurut Piaget (Desmita : 2005, hlm. 195),Pemikiran masa remaja tahap pemikiran operasional formal (formal operational thought), yakni suatu tahap perkembangan kognitif yang dimulai pada usia kira-kira 11 atau 12 tahun dan terus berlanjut sampai masa tenang atau dewasa ${ }^{e e}$. Pada masa remaja ini pula aspek sosial sangat berpengaruh terhadap perilaku dirinya. Desmita (2005, hlm. 219) menjelaskan bahwa "Perkembangan kehidupan sosial remaja ditandai dengan gejala meningkatnya pengaruh teman sebaya dalam kehidupan mereka. Sebagian waktunya dihabiskan untuk berhubungan atau bergaul dengan teman- teman sebaya mereka". Peran teman sebaya sangatlah penting bagi anak yang berada pada tahap ini. Hartup (1982; dalam Desmita, 2005, hlm. 220) mencatat bahwa pengaruh teman sebaya memberikan fungsi-fungsi sosial dan psikologis yang penting bagi remaja. Bahkan studi lain ditemukan bahwa hubungan teman sebaya yang harmonis selama masa remaja, dihubungkan dengan kesehatan mental yang positif pada usia setengah baya (Hightower, 1990; dalam Desmita, 2005, hlm. 220). 
Perspektif perkembangan remaja dari aspek psikologi maupun sosial merupakan salah satu pertimbangan pemilihan olahraga yang akan digunakan dalam proses pembelajaran penjas. Pertimbangan lainnya berdasarkan karakteristik permainan beregu, yang menyediakan situasi bermain yang kompleks dan menuntut pengambilan keputusan secara cepat dan tepat. McBride dkk. (1990, hlm. 63) menegaskan bahwa "When learners are placed in game situations that occur in open environment, that is, when conditions are constantly changing, players are required to generated cognitive strategies quickly. Racquetball, basketball, and soccer represent but a few ample of this phenomenon".

Azizmalayeri (2012, hlm. 44) mengungkapkan bahwa "Critical thinking is complex time-consuming process, requiring preparation for high-level functions". Oleh karena itu, peneliti merekomendasikan pada penelitian selanjutnya untuk melibatkan sampel yang banyak, serta waktu penelitian lebih lama karena kemampuan berpikir krtis merupakan aspek psikologis, sehingga membutuhkan waktu yang cukup lama untuk mengalami peningkatan. Berikut beberapa pertimbangan pemberian stimulasi kemampuan berpikir kritis ditinjau dari neurologi, keadaan awal, dan sosiokultural.

\section{Tinjauan Neurologi.}

Otak terdiri dari ratusan milyar sel syaraf. Sel-sel syaraf ini disebut neuron yang berukuran sangat kecil dan saling terhubung satu sama lain. Keberfungsian neuron ini akan terlihat saat neuron menerima informasi dari bagian tubuh yang lain kemudian informasi tersebut disintesiskan oleh neuron lainnya untuk dikirimkan kembali kepada bagian tubuh lainnya mengenai respon yang dilakukan sesuai dengan kondisi yang ada. Proses berpikir yang kompleks dan sadar terutama terjadi di korteks (cortex), yang terletak di bagian atas dan sisi otak. Wujudnya menyerupai rambut palsu yang tebal dan bergelombang. Bagian korteks yang terletak dekat dahi, yang disebut korteks prefrontalis (prefontal cortex), berperan penting dalam berbagai aktivitas dasar manusia, seperti proses mempertahankan atensi, penalaran, perencanaan, pengambilan keputusan, pengkoordinasian aktivitas-aktivitas yang rumit, dan pencegahan pikiran-pikiran perilaku yang tidak produktif. Bagian korteks yang lain juga tak kalah pentingnya karena terlibat dalam menafsirkan informasi visual dan auditoris, mengidentifikasi karakteristik-karakteristik spasial dari objek-objek dan peristiwa-peristiwa, dan menyimpan pengetahuan umum mengenai dunia. 
Terdapat empat poin penting mengenai peran otak dalam pembelajaran dan perkembangan kognitif, Ormrod (2001, hlm. 37) menjelaskannya sebagai berikut :

Sebagian besar pembelajaran kemungkinan melibatkan perubahanperubahan di neuron dan sinapsis; Perubahan-perubahan perkembangan yang terjadi di otak memungkinkan terjadinya proses berpikir yang semakin kompleks dan efisien; Banyak bagian otak bekerja sama secara harmonis untuk memudahkan terjadinya proses berpikir dan berperilaku yang rumit; Otak tetap mampu beradaptasi seumur hidup manusia.

Banyak peneliti meyakini bahwa landasan fisiologis pembelajaran (dan perkembangan kognitif) terletak pada perubahan-perubahan yang terjadi dalam hubungan-hubungan di antara neuron-neuron. Secara spesifik, pembelajaran seringkali melibatkan penguatan sinapsis yang ada atau pembentukan sinaps yang baru (Ormrod, 2001, hlm. 37). Pemberian masalah gerak pada penjas merupakan salah satu bentuk stimulasi untuk pembelajaran kognitif. Ormrod (2000, hlm. 37) mengemukakan bahwa "Pembentukan neuron baru tampaknya distimulasi oleh pengalamanpengalaman belajar yang baru, sekalipun perannya dalam proses pembelajaran masih belum diketahui”.

\section{Keadaan Awal Siswa}

Terdapat beberapa aspek yang kemudian berpengaruh terhadap pencapaian tujuan belajar salah satunya keadaan awal siswa.

Keadaan awal dapat dipandang sebagai kumpulan sejumlah hal yang, pada dasarnya, dapat berpengaruh terhadap proses belajar-mengajar apapun, tetapi belum tentu semuanya jadi berdampak pada belajarmengajar tertentu (keadaan awal potensial). Keadaan awal itu dapat juga dipandang sebagai komposisi sejumlah kenyataan yang terdapat pada awal proses belajar-mengajar tertentu dan nyata-nyata berpengaruh, selama guru dan siswa berinteraksi untuk mencapai tujuan instruksional khusus tertentu (keadaan awal aktual). Winkel (1999, hlm. 134)

"Intelegensi (intelligence) yaitu kemampuan menerapkan pengetahuan dan pengalaman sebelumnya secara fleksibel untuk menghadapi tugas-tugas baru yang menantang" (Ormrod, 2001, hlm. 210). 
Sternberg (dalam Ormrod, 2001, hlm. 214) membuat tiga distingsimakanya disebut triarthic. Pertama bahwa orang dapat lebih atau kurang intelegen dalam tiga bidang yang berbeda (Sternberg, 1998, 2004; Sternberg $\mathrm{dkk}$, 2000). Intelegensi analitis (analyctical intelligence) melibatkan kemampuan memahami, menganalisis, membedakan, dan mengevaluasi jenis-jenis informasi dan persoalan-persoalan yang biasanya ditemukan dalam lingkungan akademik dan tes-tes intelegensi. Inteligensi kreatif (creative intelligence) melibatkan imajinasi, penemuan, dan sintesa gagasan-gagasan dalam konteks situasi-situasi baru. Inteligensi praktis (practical intelligence) melibatkan kemampuan menetapkan pengetahuan dan keterampilan secara efektif untuk mengelola dan merespons persoalan hidup dan situasi sosial sehari-hari. Kemampuan berpikir kritis siswa yang terdapat pada penelitian ini dapat dipengaruhi pula oleh modalitas awal siswa berupa intelegensi. Pada penelitian ini, intelegensi siswa tidak diukur dan dijadikan sebagai faktor yang memang mempengaruhi skor kemampuan berpikir kritis siswa. Sehingga perlu penelitian lebih lanjut yang menyertakan variabel moderator dalam meneliti hasil belajar siswa terutama pada aspek kognitif melalui pembelajaran penjas.

\section{Perspektif Sosiokultural}

Lingkungan tempat tinggal dan tempat berinteraksi pun ikut pula berkontribusi terhadap perkembangan kognitif peserta didik. Kuhn dan Park (2005; Ormrod, 2001, hlm. 413) mengungkapkan bahwa

Nilai dan ekspektasi budaya juga kelihatannya memengaruhi kemauan dan kemampuan siswa untuk terlibat dalam pemikiran kritis. Selain itu, penekanan kultural pada harmoni kelompok bisa membuat anakanak enggan memperbincangkan perbedaan sudut pandang yang sering diperlukan dalam pemikiran kritis.

Piaget (Ormrod, 2001, hlm. 42) berpandangan bahwa interaksi sosial juga sama pentingnya bagi perkembangan kognitif. Melalui interaksi dengan orang lain yang menyenangkan (seperti percakapan) maupun yang tidak menyenangkan (seperti pertengkaran) anak-anak yang masih belia secara bertahap menyadari bahwa individu-individu yang berbeda akan memandang hal-hal secara berbeda dan pandangan- pandangan mereka tentang dunia belum tentu akurat atau logis. Proses- proses mental yang kompleks bermula sebagai aktivitas-aktivitas sosial; seiring perkembangan, anak-anak secara berangsur-angsur menginternalisasikan proses-proses yang mereka gunakan dalam konteks- 
konteks sosial dan mulai menggunakannya secara independen (Vygotsky dalam Ormrod, 2001, hlm. 57). Teori Vygotsky meyakini bahwa orangorang dewasa di masyarakat mendorong perkembangan kognitif anak secara sengaja dan sistematis. Orang dewasa secara berkesinambungan melibatkan anak-anak dalam aktivitas-aktivitas tersebut dengan sukses. Vygotsky menekankan pentingnya masyarakat dan budaya mendorong pertumbuhan kognitif sehingga teorinya terkadang disebut sebagai perspektif sosiokultural (Ormrod, 2008, hlm. 55).

Pada proses pembelajaran pendidikan jasmani, siswa akan sangat dipengaruhi oleh situasi sosial yang dinamis, sehingga peran sosial terhadap pembelajaran sangatlah mempengaruhi perilaku individu untuk menerima materi pembelajaran. Pada masa remaja ini pula aspek sosial sangat berpengaruh terhadap perilaku dirinya. Desmita (2005, hlm. 219) menjelaskan bahwa "Perkembangan kehidupan sosial remaja ditandai dengan gejala meningkatnya pengaruh teman sebaya dalam kehidupan mereka. Sebagian waktunya dihabiskan untuk berhubungan atau bergaul dengan teman-teman sebaya mereka". Peran teman sebaya sangatlah penting bagi anak yang berada pada tahap ini. Hartup (1982; dalam Desmita (2005, hlm. 220) mencatat bahwa pengaruh teman sebaya memberikan fungsi-fungsi sosial dan psikologis yang penting bagi remaja. Bahkan studi lain ditemukan bahwa hubungan teman sebaya yang harmonis selama masa remaja, dihubungkan dengan kesehatan mental yang positif pada usia setengah baya (Hightower, 1990; dalam Desmita, 2005, hlm. 220).

Peran guru pun sangat diperlukan dalam memfasilitasi pengalaman belajar yang menyenangkan dan mampu menstimulasi kemampuan berpikir kritis. Colln-Appling dan Giuliano (2017) mengemukakan bahwa "Early in the educational journey, educators would benefit from designing and implementing simulation exercises that encourage students use of attributes related to the development of critical thinking skills". Penelitian Gholami dkk (2016) menunjukkan bahwa terdapat peningkatan skor berpikir kritis terutama pada tahap evaluasi dan deduksi, juga pada skor kesadaran metacognisi siswa keperawatan setelah mengalami pembelajaran berbasis masalah. 


\section{KESIMPULAN}

Berdasarkan hasil kajian teoritis dan berbagai hasil penelitian, dapat disimpulkan bahwa pembelajaran penjas dapat menstimulasi kemampuan berpikir kritis melalui proses pembelajaran berbasis masalah. Pembelajaran penjas sendiri tentu belum cukup, karena proses kemampuan berpikir kritis memerlukan proses yang panjang dan relatif lama serta perlu dukungan dari semua pihak. Maka, perlu ada kesinambungan antara mata pelajaran penjas dengan mata pelajaran lain yang juga saling mendukung dalam memberikan pembelajaran berbasis masalah dalam mencapai tujuan pendidikan nasional sesuai dengan kurikulum yang berlaku. 


\section{REFERENSI}

Azizmalayeri dkk. (2012). The Impact of Guided Inquiry Methods of Teaching on The Critical Thinking of High School Students. Journal of Education and Practice: Vol 3. No. 10.

Colln-Appling dan Giuliano. (2017). A Concept Analysis of Critical Thinking: A guide for Nurse Educators. Nurse Education Today: 49, 106-109. Online : www.elsevier .com

Cottrell, S. (2005). Critical Thinking Skills. New York: Palgrave Macmillan Ltd.

Desmita. (2005). Psikologi Perkembangan. Bandung: PT. Remaja Rosdakarya.

Ennis, R H. (1985). A Logical Basis for Measuring Critical Thinking Skills. Educational Leadership (44-48.)

Gallahue, D L. (1996). Developmental Physical Education for Today's Children. USA: Times Miror Higher Education Group, Inc.

Gholami et al. (2016). Comparing The Effects of Problem-Based learning and The Traditional Lecture Method on Critical Thinking Skills and Metacognitive Awareness in Nursing Students in a Critical Care Nursing Course. Nurse Education Today: 45 16-21. Online : www.elsevier.com

McBride, dkk. (1990). Teaching Critical Thinking Skills in the Psycomotor Domain. The Clearing House :Vol. 63 (197-201).

Ormrod, J E. (2008). Psikologi Pendidikan (Edisi Keenam-Jilid 1). Bandung: Erlangga.

Walkuski, J J. (2013). Critical Thinking in Physical Education. Teaching and Learning, 18 (1), 83-92.

Winkel, W S. (1999). Psikologi Pengajaran. Jakarta: PT. Grasindo. Yildirim, Ahmet. (2003). Analysis of Academic Learning Time in Physical Education Classes of Prospective and Inservice Teachers. Thesis Master: tersedia http://etd.lib.metu.edu.tr/upload/1067594/ index.pdf 